\title{
The impact of family planning household service delivery on women's status in Bangladesh
}

James F. Phillips

Population Council

Mian Bazle Hossain

Follow this and additional works at: https://knowledgecommons.popcouncil.org/departments_sbsr-pgy

Part of the Demography, Population, and Ecology Commons, Family, Life Course, and Society Commons, International Public Health Commons, and the Maternal and Child Health Commons How does access to this work benefit you? Let us know!

\section{Recommended Citation}

Phillips, James F. and Mian Bazle Hossain. 1998. "The impact of family planning household service delivery on women's status in Bangladesh," Policy Research Division Working Paper no. 118. New York: Population Council. 


\section{The Impact of Family Planning H ousehold Service Delivery on Women's Status in Bangladesh}

James F. Phillips

Mian Bazle H ossain

1998 No. 118 


\title{
The Impact of Family Planning Household Service Delivery on Women's Status in Bangladesh
}

\author{
James F. Phillips \\ Mian Bazle Hossain
}

James F. Phillips is Senior Associate, Policy Research Division, Population Council. His e-mail address is jphillips@popcouncil.org. Mian Bazle Hossain is a Doctoral Candidate in the Department of Social Statistics, University of Southampton, Southampton, UK. 


\begin{abstract}
Since 1982, the Maternal and Child Health and Family Planning Extension Project in Bangladesh has compiled longitudinal panel data on rural women's contact with household service providers who visit homes to discuss family planning and offer services to women on request. This study tests the hypothesis that home-based services reinforce customs of purdah (female seclusion) by sustaining the dependency and isolation of the women served by the program. Results show that household services improve women's status. This effect is largely attributable to the impact of outreach on effective fertility regulation. Findings do not support the hypothesis that household service delivery is detrimental to women's status in Bangladesh. Policy implications of this research are discussed.
\end{abstract}

This material may not be reproduced in any form without written permission from the authors. 
For two decades, the government of Bangladesh has hired, trained, and deployed married women to visit rural households, consult with couples about family planning, and provide contraceptive services in their homes to those who adopt a method. Fully 28,000 of these workers, known as family welfare assistants (FWAs), are currently working in hamlets throughout Bangladesh. ${ }^{1}$ Research has established that FWA outreach fosters family planning awareness, contraceptive adoption, and continuity of use, suggesting that the FWA program has achieved many of its original objectives. Contraceptive knowledge is virtually universal throughout Bangladesh, nearly half of all women are contraceptive users, and FWA doorstep services constitute a major source of supply of all commodities in use. ${ }^{2}$ The onset and pace of the rapid demographic transition in Bangladesh has likely been influenced by this program. ${ }^{3}$ Despite the apparent demographic success of the FWA initiative, this program has recently become controversial on gender grounds. A widely cited ethnographic appraisal by Schuler et al. (1995) argues that the direct effects of the household FWA visitation regime may constrain rather than enhance women's status by reinforcing the customs of patriarchy and purdah (female seclusion). ${ }^{4}$ By reinforcing patriarchal institutions, houseto-house outreach may keep women isolated and vulnerable. In this sense, FWA outreach is detrimental to women's status.

This paper re-examines this proposition with a statistical analysis testing the hypothesis that women's status has been adversely affected by FWA home visits. Two cross-sectional women's-status surveys conducted in two rural thanas (administrative districts which serve a population of about 300,000) are used, in conjunction with longitudinal data recording exposure, to assess the impact of FWA visits during the period from 1982 to 1993 on women's status in 1988 and 1993.

\section{THE SCHULER ET AL. STUDY}

The investigation by Schuler and her colleagues is based on social survey data collected in six villages, three of which are in a district of northern Bangla- 
desh; the remaining three are in two districts of western Bangladesh. The work areas of seven FWAs are encompassed by the study area: One village had a worker from a nongovernmental program, one had a government and a nongovernmental worker, and four villages had government FWAs only. Study households were visited by male and female interviewers, and the sample was purposely selected, with procedures designed to maximize the odds that a sample household would have at least one contraceptive user. Households selected for the study included at least one married woman aged 35 or younger with at least one living child; households with couples older than 35 and those with no couples under 35 were excluded. The sampling frame was limited to households with less than one acre of land in order to concentrate interviewing among the poor and landless. This procedure produced a sample of 104 women and 92 men who were interviewed in depth. An additional 47 women and their husbands from a neighboring village who were practicing contraception were selected from a universe that was matched to the sample in terms of socioeconomic status. Thus, the study was based on 151 interviews of relatively young, low-parity couples, predominantly contraceptive users from rural households of low economic status.

The interview responses from this sample elicited a number of observations about limitations of the FWA program as well as recommendations for change. ${ }^{5}$ The key theme of the study is that woman-centered FWA strategies foster dependencies on men, service providers, and traditional familial institutions. By working within the patriarchal system, the FWA program has inadvertently reinforced social institutions that structure gender stratification. A woman who is compelled to leave her village for services is exposed to extrafamilial communication and influences, a process that fosters independence, autonomy, and mobility. The following passage from the paper summarizes this view (Schuler et al. 1995: 137):

In its intensive focus on family planning services for women ... the program fails to disturb and may even reinforce the patriarchal struc- 
tures that keep women isolated and vulnerable. Our findings illustrate some of the situations in which women become trapped, both because of their economic dependence on men and because of the larger system of gender inequality in which that dependence is rooted. Contraception cannot solve the larger problem of women's subordination, which we believe should be addressed more directly.

While Schuler and her colleagues acknowledge that the program's accommodation to prevailing social norms "was not necessarily a mistake," the implication of their study is that the FWA program does more harm, on gender grounds, than good. ${ }^{6}$ They argue that the FWA program has been a demographic success that is nonetheless a gender failure. Although doorstep service delivery does not harm women's status directly, in this view, it prevents improvements in status that would have occurred if women had been required to leave their homes and travel to clinics for services, thereby failing to disturb and possibly reinforcing the patriarchal structures that keep women secluded from the world and vulnerable.

The paper's hypothesis of detrimental gender effects challenges other prominent views on the gender impact of the FWA program arguing that outreach has a direct positive effect on women's autonomy through client-provider exchanges. In this alternative view, women who are isolated and confined by the customs of patriarchy and purdah benefit from extrafamilial FWA-initiated social encounters. External ideas, role models, and social support provided by FWA encounters foster improvements in women's status that would not otherwise occur. ${ }^{7}$ Moreover, fertility regulation has effects on women's status that arise from enabling women to plan the timing and number of births (for example, see Davis 1984). Because FWA outreach has fostered reproductive change, outreach may have had indirect gender effects by freeing women from the burden of unwanted fertility.

Appraisal of the hypothesis of FWA program gender effects should address the various limitations of existing research on this issue. Hypothesis testing 
requires a study sample that is representative of a large population. Purposeful sampling of poor households with young women who are practicing contraception may have biased the Schuler et al. investigation or other studies based on special project areas with unusual service-delivery systems. Clustering problems may further complicate the interpretation of results from ethnographic studies, because inference is based on clients' exposure to very few FWAs. The study area should be dispersed so that interpretation is not based on the work of a small, clustered, and statistically unrepresentative number of FWAs. The number of respondents should be sufficient for statistical inference. Moreover, testing an hypothesis of adverse gender effect requires a longitudinal study. Detrimental gender effects are likely to be subtle, cumulative, and gradual. Cross-sectional research may be appropriate for exploratory work designed to generate hypotheses, but hypothesis testing requires examination of the cumulative effects of different experiences of FWA outreach over a period of several years. Finally, examining net effects rather than gross relationships is important. Women's status is influenced by their own and their husbands' educational attainment, by their households' economic status, by their religion, by their past fertility-control practices, and by other background characteristics that can contaminate an appraisal of the role of outreach as a determinant of status (Balk 1997). Regression methods are indicated.

\section{THE DATA}

\section{The Study Population}

The data for the present study were compiled in the course of the ongoing $\mathrm{MCH}-\mathrm{FP}$ Extension project of the International Centre for Diarrhoeal Disease Research, Bangladesh (ICDDR,B), a collaborative endeavor with the Government of Bangladesh in Sirajganj and Abhoynagar thanas. ${ }^{8}$ Background characteristics of the study population were ascertained in a 1982 baseline survey and 
reassessed at various times. The present analysis is structured as a cohort study of 3,783 women who were interviewed in 1982 and followed until 1993 (see Table 1).

The baseline assessment shows that educational attainment was low, but typical of Bangladesh national data. Indicators of household economic status, women's economic activity, and possession of modern objects are also typical of national data. Programmatic characteristics reported in the table reflect exposure

Table 1 Background characteristics of respondents and programmatic characteristics, MCH-FP Extension Project, ICDDR, B, Bangladesh

\begin{tabular}{lll}
\hline Variable & Mean $^{\mathrm{a}}$ & Proportion $^{\mathrm{a}}$ \\
\hline
\end{tabular}

Background characteristics (1982)

Age

Educational attainment (number of years)

Husband's educational attainment (number of years)

Household unit area (sq. ft.)

Religion: non-Muslim

Work outside the home

Desire no additional children

Possess a radio $29.2 \quad(30.2)$

$254.9(250.5)$

Use tube well as source of drinking water

Subdistrict: Abhoynagar

Programmatic characteristics

Number of contacts with FWA, 1988-93

16.6

Number of rounds observed, 1988-93

16.5

Number of rounds of contraceptive use prior to 1988

Number of rounds of contraceptive use, 1988-93

6.4

Total number of cases $(\mathrm{N})$
$0.13(0.14)$

$0.37(0.26)$

$0.62(0.69)$

$0.29(0.22)$

$0.96(0.73)$

$0.46(0.43)$

MCH-FP = Maternal and Child Health-Family Planning. ICDDR, B = International Centre for Diarrhoeal Disease Research, Bangladesh. FWA $=$ Family Welfare Assistant.

${ }^{a}$ Means and proportions for the original 1982 sample are given in parentheses. 
to the program over the 11-year study period. On average, women in this cohort were exposed to 17 contacts, or approximately one visit each quarter. About onethird of the period of observation was associated with contraceptive use.

\section{Measurement of Women's Status}

Although the Extension Project is focused on service-delivery research topics, gender research has also been a key focus of field investigations. Bangladesh is a patriarchal social setting where women's status is constrained by the customs of marriage, traditions of modesty, and the practice of purdah (White 1992; Abdullah and Zeidenstein 1982; Kabeer 1988; Adnan 1993; Amin 1997; Cain et al. 1979). Analyses of international survey data indicate that women's status in Bangladesh is low relative to other Asian settings (Curtin 1982). The low status of women is known to explain important maternal and child health problems (Lindenbaum 1968). In this context, poorly supervised and inadequately trained workers can cause social discord or unanticipated problems for women (Simmons and Mita 1992). Concerns about the social impact of family planning services generated interest in the developing gender survey research components of the Extension Project.

The core statistical resource of the Extension Project is the Sample Registration System (SRS). Launched in two study thanas in 1982, the SRS compiles data on contraceptive-use dynamics, government health and family planning workers' contact with rural women, and demographic events (such as births, deaths, and migrations). In addition, the longitudinal SRS system provides a framework for the management and analysis of cross-sectional surveys conducted at various times about different issues (Mozumder et al. 1991). Two of the SRS cross-sectional surveys were devoted to research concerning women's status. Because these data are linked to the longitudinal SRS, archival data permit research on the role of women's status as a determinant or consequence of contraceptive behavior and fertility. The first of these studies, known as the Women's Status Survey (WSS), was conducted in 1988; the second survey, known as the In-depth Survey 
(IDS), was conducted in 1993. Both surveys included questions about indicators of respondents' autonomy and status within their households. Although questions in the two surveys were not identical, the women's status components of the interviewing instruments in the two studies were similar. The present study follows procedures proposed by Balk for the analysis of women's status (Balk 1991, 1994, and 1997). Scores for four indicators of women's status were prepared using responses to questions on women's status. By linking data from the WSS and IDS to the longitudinal histories of outreach field-workers' contact with rural women, the relationship between this contact and changes in women's status during the 1988-93 period can be examined.

\section{Data Limitations}

A limitation of this study concerns the problem of censoring and sample loss. The original Extension Project sample was a random stratified cluster sample of the population of Sirajganj and Abhoynagar thanas resulting in the selection of 5,600 women of reproductive age. Stratification was designed to ensure that sample areas would cover all work areas of FWAs assigned to the two study thanas. In 1988, severe flooding of the Jamuna river, permanently displaced 602 respondents. An additional 1,215 women moved from the study area over the 11-year period or were lost to the study for other reasons such as migration or death, or were not interviewed for the WSS or the IDS for these reasons or because of temporary absence. Despite this loss, however, the characteristics of the study sample and the original 1982 baseline sample are similar (see Table 1). Of the variables reported in the table, work outside the home was the most affected by sample loss. Of the original sample, 26 percent worked outside the home, versus 37 percent recorded in the final data set. This finding suggests that the 1988 floods and respondents' mobility between surveys may have biased the sample in subtle ways so as to influence estimates of the magnitude of effects. Sample loss will not change the estimated direction of regression effects, however. 
Analytical procedures must take into consideration that the WSS and IDS are different sorts of survey instruments used to explore the common theme of women's status. As Table 2 shows, 17 indicators of women's status are available from the WSS and 19 are available from the IDS. Of these indicators, four are common to both surveys. The WSS was designed to explore detailed components of women's status, whereas the IDS collected less specific data on this theme. The present analysis uses this information by constructing WSS scales for women's status in 1988 to be used as baseline control variables and a general IDS women's-status scale in 1993 as the dependent variable.

Table 2 Women's status indicators, 1988 Women's Status Survey (WSS) and 1993 In-depth Survey (IDS), Bangladesh

Proportion

Survey/indicator question

19881993

\section{WSS}

Does respondent have permission to go outside to

Earn money

0.13

Visit parents

0.99

Visit relatives

0.99

Adopt family planning

0.50

Does respondent make decisions about

Spending money for medicine when a child is sick

0.25

Keeping a child in school

0.17

To whom/at what age a daughter should be married

0.15

Spending money she earned

0.70

Spending money her husband earned

Does respondent approve of women in this society who

Travel on their own

Earn money while working at home

Work outside the home-professional

Work outside the home-for survival

Make decisions about their own or a sick child's medical treatment

0.66

Own some property 
Does respondent have autonomy to

Travel outside her household 0.98

Travel outside her village $\quad 0.77$

Travel unaccompanied $\quad 0.40$

Travel outside without a burka (scarf) $\quad 0.83$

IDS

Did respondent travel outside her village in the last six months to

See a film

Attend a women's meeting

Go to a health center

Go to thana sadar for visiting/shopping

Does respondent have permission to go outside her village to

Attend a women's meeting

Go to a health center

Go to thana sadar for visiting/shopping

Did the respondent

Meet a male nonrelative in last six months

Take a sick child to the hospital by herself

Who usually makes decisions with regard to

Purchasing or selling cattle

Purchasing or selling land

Borrowing or lending (cash/kind)

Going to parent's house

The number of children to have

Timing of children's births

\section{Questions asked in both surveys}

Does respondent have permission to

$\begin{array}{lll}\text { Take a sick child to a hospital outside the village } & 0.41 & 0.35\end{array}$

$\begin{array}{lll}\text { Greet a male nonrelative visitor at her home } & 0.42 & 0.84\end{array}$

$\begin{array}{lll}\text { Go outside her village to see a film } & 0.24 & 0.92\end{array}$

Does respondent usually make the decision to 
Deterioration in women's status was constructed from the overlapping indicators that were observed in 1988 and 1993. Regressions based on the scales use all indicators in Table 2. Scales were constructed by summing dummy variables corresponding to each indicator. For the WSS, the women's status scale varies from 0 to 23; for the IDS, the corresponding scale varies from 0 to 19.

\section{THE ANALYSIS}

Two models of the effects of FWA household outreach on women's status are posited in the regressions below. Model 1 assesses the cumulative effect of exposure to FWA visitation. Regression parameters test the hypothesis that greater exposure constrains women's status over the duration of the Extension Project relative to women's status among those who are less exposed, controlling for other determinants of women's status. The less-exposed group represents a construct of the missed opportunity that could arise when women seek services on their own. If Schuler et al. are correct, those who are more often exposed to FWA visits will have lower status, other things being equal. Because endogeneity could arise from the selectivity of FWA visitation, we posit a model of change in women's status in which behavior and outreach implicitly adjust for selectivity. ${ }^{9}$ A framework illustrating selectivity and determinants in FWA outreach relationships is presented in Figure 1. Women's status is shown to be a consequence of various exogenous sociodemographic factors that affect contraceptive use, worker-client exchanges, and women's position. Over time, contraceptive use is a consequence of worker-client exchanges and also a determinant of these changes. Similarly, women's status is both a consequence and a determinant of worker-client exchanges and contraceptive use. Taken together, these influences and consequences are captured by a statistical model that tests the possibility that variation in women's status in 1993, net of women's status in 1988, is explained by FWA outreach over the 1988 to 1993 period: 
Figure 1 Analytical framework for the impact of contacts from family welfare assistant (FWA) household outreach on components of the status of women, Maternal and Child Health-Family Planning Extension Project, Bangladesh

\section{Respondent's background characteristics \\ -Age \\ -Education \\ -Husband's education \\ -Dwelling area \\ -Religion \\ -Works outside the home \\ -Desires no more children \\ -Possesses a radio \\ -Uses tube well as source of drinking water \\ -Subdistrict: Aboynagar}

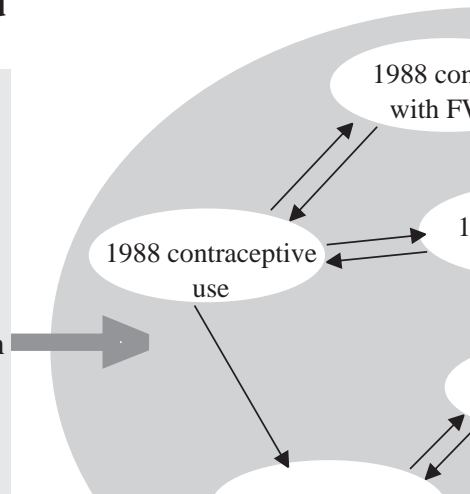

1993 contraceptive use
1988 women's

status

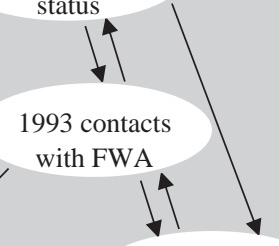

1993 women's

$$
S_{i j t}=\alpha+\sum_{j=1}^{J} \beta_{j} s_{i j 0}+\gamma_{1} \sum_{k=1}^{K} x_{i k}+\gamma_{2} \sum_{k=1}^{K} c_{i k}+\sum_{l=1}^{L} \delta_{l} z_{i l 0}+\varepsilon_{i},
$$

where

$$
\begin{aligned}
s_{i j 0}= & \text { the status of individual } i \text { as of time } 0 \text { in the } 1988 \text { WSS survey for the } \\
& j \text { th indicator of women's status among } J \text { such indicators; } \\
x_{i k}= & \text { the number of times individual } i \text { was observed over } K \text { possible times } \\
& \text { that observations could occur between } 1988 \text { and 1993; } \\
c_{i k}= & \text { the intensity of contacts over } K \text { possible observations of individual } i \text {; } \\
z_{i l 0}= & \text { the } l \text { th baseline characteristic of individual } i \text { among } L \text { such indica- } \\
& \text { tors; and } \\
\varepsilon_{i}= & \text { an error term. }
\end{aligned}
$$


$S_{i j t}$ measures overall cumulative women's status of individual $i$ in the 1993 IDS. The estimated parameter $\gamma_{2}$ assesses the effect of contact, controlling for baseline status, which is equivalent to assessing the effect of contact on changing status. Parameters of (1) are to be estimated by ordinary least squares.

Model 2 examines the process of change by acknowledging that deteriorating status, although uncommon, may be associated with FWA outreach. To examine the determinants of deterioration in women's status, all women are scored according to their relative status in 1988 and 1993 for the four indicators in Table 2 that overlap in the WSS and the IDS. Lower status on any indicator is scored as 1 and 0 otherwise. Model 2 is an analysis of the determinants of each discrete indicator of deteriorating status. If the FWA detrimental-effect hypothesis is valid, we expect deteriorating status to covary with the intensity of FWA outreach. Model 2 is a logit regression model of the form:

$$
\operatorname{logit} D_{i t}=\alpha^{*}+\gamma_{1}^{*} \sum_{k=1}^{K} x_{i k}+\gamma_{2}^{*} \sum_{k=1}^{K} c_{i k}+\sum_{l=1}^{L} \delta_{1}^{*} z_{i l 0}+\varepsilon_{i}^{*},
$$

where

$D_{i}=$ a discrete indicator of deteriorating women's status in terms of autonomy for any of the four indicators, and zero otherwise for the time interval 0 to $t ; x_{i k}, c_{i k}, z_{i l 0}$, and $\varepsilon_{i}^{*}$ are defined as in Model 1, and $\alpha^{*}, \gamma^{*}$, and $\delta^{*}$ are unknown parameters for estimation by maximum likelihood.

All models adjust for exogenous determinants of women's status, such as educational attainment, household economic status, and demographic characteristics, as in $z_{i l 0}$ in Models 1 and 2. Model 1 is estimated with and without contraceptive use to assess the role of fertility regulation as a determinant of women's status.

Table 3 reports a comparison of women's status in 1988 and 1993 according to the four indicators of women's status in the WSS and the IDS that overlap. The table suggests that women's status improved for the four overlapping indica- 
Table 3 Percentage distribution of changes in women's status over the 1988 to 1993 period, by type of change, according to four women's status indicators from two surveys, MCH-FP Extension Project, ICDDR, B, Bangladesh, 1988 and 1993

\begin{tabular}{|c|c|c|c|c|c|c|c|c|c|c|}
\hline \multirow{2}{*}{$\begin{array}{l}\text { Type of } \\
\text { status change }\end{array}$} & \multicolumn{2}{|c|}{$\begin{array}{c}\text { Take sick } \\
\text { child to } \\
\text { hospital out- } \\
\text { side village }\end{array}$} & \multicolumn{2}{|c|}{$\begin{array}{c}\text { Greet male } \\
\text { nonrelative } \\
\text { at her home }\end{array}$} & \multicolumn{2}{|c|}{$\begin{array}{c}\text { Go outside } \\
\text { village to } \\
\text { see film }\end{array}$} & \multicolumn{2}{|c|}{$\begin{array}{c}\text { Visit a } \\
\text { doctor } \\
\text { when sick }\end{array}$} & \multicolumn{2}{|c|}{$\begin{array}{c}\text { Any } \\
\text { indicator }\end{array}$} \\
\hline & $\%$ & $(\mathbf{N})$ & $\%$ & $(\mathbf{N})$ & $\%$ & $(\mathbf{N})$ & $\%$ & $(\mathrm{~N})$ & $\%$ & $(\mathbf{N})$ \\
\hline Deterioration & 8.4 & (316) & 1.0 & (39) & 0.3 & (13) & 10.4 & (394) & $7.5^{\mathrm{a}}$ & (286) \\
\hline No change & 72.2 & $(2,730)$ & 47.8 & $(1,808)$ & 47.9 & $(1,811)$ & 51.8 & $(1,961)$ & $18.7^{\mathrm{b}}$ & (706) \\
\hline Improvement & 19.4 & (737) & 51.2 & $(1,936)$ & 51.8 & $(1,959)$ & 37.8 & $(1,428)$ & 73.8 & ,791) \\
\hline Total & 100.0 & $(3,783)$ & 100.0 & $(3,783)$ & 100.0 & $(3,783)$ & 100.0 & $(3,783)$ & 100.0( & $(3,783)$ \\
\hline
\end{tabular}

a Deterioration on any indicator, improvement on none; ${ }^{b}$ Mixed, no change, deterioration, or improvement; "improvement on any indicator, deterioration on none.

tors in the two studies. Of the 3,783 women interviewed, 19 percent indicated improvement in autonomy, about half indicated improvements in household authority and indicators women's status attitudes, and nearly 40 percent indicated improvement in mobility. Relatively few women reported responses consistent with deteriorating status, although fully 8 percent reported deteriorating autonomy over the 1988 to 1993 period and 10 percent reported deteriorating mobility. Changes summarized in Table 3 provide the dependent variables for Model 2. A series of dummy dependent variables for Model 2 is implied by "deterioration" on one or more of the indicators in the top row of Table 3.

\section{RESULTS}

Table 4 reports regression results for the estimation of Model 1. Parameters demonstrate the selectivity of outreach: Women of higher status are more likely to be visited by FWAs than are women of lower status. Results are largely consistent with other studies of the determinants of women's status that show that educational attainment, Hindu household religion, women's work outside 
Table 4 Ordinary least-squares regression of the effect of exposure to FWA contacts over the 1988-93 period on women's status in 1993, controlling for women's status components in 1988, for background characteristics, and for contraceptive use, MCH-FP Extension Project, ICDDR, B, Bangladesh

\begin{tabular}{lcc}
\hline & \multicolumn{2}{c}{ Model 1 OLS } \\
\cline { 2 - 3 } Independension coefficients
\end{tabular}

\section{8 women's status indicators}

Autonomy: Does respondent have permission to

Take a sick child to hospital outside the village

$\begin{array}{ll}0.727 * * * & 0.675^{* * *} \\ -0.137 & -0.089 \\ 0.429 * * & 0.409 * * \\ 0.645 & 0.748 \\ 1.113 & 1.078 \\ 0.842 * * * & 0.838 * * * \\ & \\ 0.249 * & -0.030\end{array}$

Authority: Does respondent make decisions about

Spending money for medicine when a child is sick

$\begin{array}{cc}0.320 & 0.326 \\ -0.214 & -0.186 \\ 0.526^{*} & 0.524^{*} \\ & \\ -0.029 & -0.085 \\ -0.039 & -0.048 \\ 0.361 & 0.316\end{array}$

Seeing a doctor when she, herself, is sick

Keeping a child in school

To whom/at what age a daughter should

be married

Attitude: Does respondent approve of women in this society who

Travel on their own

Earn money while working at home

Work outside the home-professional

$0.509^{* * *}$

$0.519 * * *$

Work outside the home-for survival

$-0.175$

$-0.170$

Make decisions about their own or a sick child's medical treatment

$0.472 * * *$

$0.418 * * *$

Own some property

0.147

0.143 


\section{Model 1 OLS regression coefficients}

Independent variable

Mobility: Does respondent have autonomy to

Travel outside her household

Travel outside her village

Travel unaccompanied

Travel outside without a burka (scarf)
Contraception omitted

0.566

$-0.167$

$0.514 * * *$

0.420

$-0.011$

$0.178^{* * * *}$

$-0.035$

0.114

$0.688 * * *$

$0.316 * *$

$-0.002 * * *$

$-0.008$

$0.611 *$

$-0.106$

$0.024 * * *$

$-0.082$

Number of rounds observed, 1988-93

Possesses a radio

Uses tube well as a source for drinking water

Subdistrict: Abhoynagar

\section{Programmatic characteristics}

Number of contacts with FWA, 1988-93

0.082
Contraception included

Number of rounds of contraceptive use prior to 1988

-

Number of rounds of contraceptive use, 1988-93

$\mathrm{R}^{2}$

0.131

0.145

Adjusted $\mathrm{R}^{2}$

0.123

0.137

$\mathrm{F}$ value

$16.12 * * *$

$17.17 * * *$

$(\mathrm{N})$

Degrees of freedom

$37 / 3,745$

$37 / 3,745$

Intercept

$8.007 * * *$

$8.719 * * *$

*Significant at $\mathrm{p} \leq 0.05 ;{ }^{* *} \mathrm{p} \leq 0.01 ; * * \mathrm{*} \leq 0.001 . \quad-=$ Not applicable. 
the home, and wanting no more children are associated with women of higher status. Inverse relationships are associated with indicators of higher household economic status (as measured by dwelling unit floor space), household health behavior (as measured by tube-well use), and husband's schooling at the primary level. Abhoynagar is a relatively developed thana with a substantial nonagricultural component in its economy. Women who live in Abhoynagar are of higher status than are women in Sirajganj. Households with modern views of health and child welfare are likely to invest in tube wells or to seek safe water sources. As Table 4 shows, women who reside in such households are of higher status than are women who reside in more traditional households. FWA contacts have no net effect on 1993 status if contraceptive use is excluded from the model. Effects are positive and significant if contraception is included. Thus, the findings do not support the hypothesis that FWA visits have detrimental effects on women's status. Rather, results are consistent with the hypothesis that FWA household outreach fosters improved status for women.

The regressions on women's status scores reported in Table 4 are estimated with and without contraceptive use. Results clarify the mechanisms through which FWA outreach affects women's status. Significance tests show that the positive effect of FWA outreach on women's status is subsumed under the contraceptive effect. This result suggests that effects on women's status arise mainly from the impact of FWA visitation on improved fertility regulation.

Table 5 presents results from the Model 2 logit regression assessing the covariates of deterioration in women's status. Although likelihood chi-square tests show that regressions significantly improve the overall fit of models, deterioration in status is not associated with respondent's age, educational attainment, husband's education, women's working status, or household economic status. When status deteriorated, Hindu women and Abhoynagar women were more likely to be affected than were other women. Results show that FWA outreach neither fosters nor prevents deteriorating status. Instances of diminishing au- 
Table 5 Logistic regression analysis of the deterioration of women's status over the 1988-93 period, controlling for the effect of respondents' characteristics, MCH-FP Extension Project, ICDDR, B, Bangladesh

Independent variable

Deterioration on any indicator

\section{Background characteristics}

Age

30-39 years

0.99

$>39$ years

0.77

Education

Primary

1.15

$>$ Primary

Husband's education

Primary

1.08

$>$ Primary

1.02

Religion: Non-Muslim

$1.33^{*}$

Additional children: Wants no more

0.96

Household economic status

Household unit area (sq. ft.)

1.00

Tube well water source

0.96

Household possesses radio

0.88

Works outside the home

0.94

Region: Abhoynagar thana

$2.44 * * *$

\section{Programmatic characteristics}

Total number of contacts with FWA, 1988-93

1.01

Total number of rounds observed, 1988-93

0.96

Number of rounds of contraceptive use prior to 1988

$0.99 *$

Number of rounds of contraceptive use, 1988-93

1.00

-2 Log likelihood

3451.4

$\chi^{2}$

$157.4 * * *$

(N)

Degrees of freedom

Intercept $-1.51$

* Significant at $\mathrm{p} \leq 0.05 ; * * * \mathrm{p} \leq 0.001$. 
tonomy, authority, or mobility have no relationship with FWA activities. The hypothesis of detrimental FWA effects is not supported by models of the determinants of deteriorating status.

\section{CONCLUSION}

For two decades, village family welfare assistants have provided family planning services to women in their homes throughout Bangladesh. This program has achieved a measure of success: FWA services have contributed to contraceptive use, expanded contraceptive choice, and exposed women to extrafamilial ideas and social contacts. ${ }^{10}$ Schuler et al. have alerted the policy community to a potential problem with this approach: Home services may reinforce patriarchal traditions that would otherwise erode if women were required to travel to clinics for services. The implication of this view is that women who are more often exposed to FWA services will be less mobile, autonomous, and assertive than women who are relatively unexposed. The present study has employed statistical methods for the analysis of a large-scale, longitudinal, randomized probability sample to examine this hypothesis.

Two regression models of hypothesized detrimental FWA effects were estimated in this paper: Cumulative dose effects and deteriorating status effects. No support has been found for the hypothesis that family planing outreach has had a detrimental effect on women's status in rural Bangladesh. For a cohort of 3,783 women observed for an 11-year study period, cumulative exposure to FWA visitation is associated with improved women's status at the end of this period. This finding is partially explained by the effect of outreach on fertility regulation and by the improved status of women that is associated with reproductive planning. This effect arises, in turn, from the enhanced mobility and autonomy that is associated with effective fertility regulation. When deterioration in status was examined as the outcome, results showed that exposure to outreach is associated 
with no effect on the odds of deteriorating status. Both models, in summary, suggest that women's status is enhanced by household outreach services.

The primary mechanism through which outreach improves women's status is effective fertility control that enhances mobility, autonomy, and household authority over time. Research has demonstrated that the FWA program sustains contraceptive use by broadening method choice, improving access, and diminishing contraceptive discontinuation. A program reoriented to passive services may lose elements of support for contraception that FWAs now provide to women in their homes. A less effective family planning outreach program would deprive women of the gender benefits of effective fertility regulation demonstrated in this analysis. A program that is effective in providing family planning also benefits women by enhancing their status. These findings attest to the need for caution in interpreting the policy implications of recent ethnographic research suggesting that household outreach reinforces patriarchal structures and impedes gender development. The Bangladesh family planning program is in the process of changing the FWA household visitation program into a passive depot approach, abandoning the policy of doorstep FWA services. Such changes must be based on experimental research showing that the new policies benefit women more than the existing program. As yet, however, no experimental study has demonstrated gender benefits over the current program. Because the present analysis adds gender to the list of domains of benefits that accrue from household contraceptive service delivery, establishing that similar gender benefits arise from static service policies is important before a large-scale change is instituted.

One of the limitations of the FWA program is its fragile institutional grounding. All FWAs are temporary contractual workers whose work is supported by external donors. Other public service programs are staffed mainly by tenured male civil servants who are funded from the Bangladesh revenue budget. Although Schuler et al. have never recommended the firing of FWAs, their argu- 
ment for the redeployment of FWAs is based on the hypothesis that FWA outreach to women in their homes does more harm on gender grounds than good. This unsubstantiated argument has diminished commitment to the FWA initiative, particularly in private voluntary agencies where substantial layoffs of FWA are already in progress. If the Schuler et al. hypothesis is accepted at face value by the policy and donor community, a program that deploys 28,000 rural women could be discredited, fostering policy changes that cause women to lose their jobs in a setting where no alternative employment opportunities exist. ${ }^{11}$ Pursuing policies that compel women to travel to clinics for family planning services with the aim of liberating them from patriarchal familial influences may fail to achieve gender goals. Instead, many women will simply stay at home to avoid the costs of travel, to escape from the hassles of clinical encounters, and to have children.

\section{Notes}

1 Nongovernmental organizations (NGOs) also have been actively engaged in deploying female outreach workers. Estimates of their numbers differ, but as many as 10,000 additional outreach workers may be deployed by NGOs.

2 Various studies have indicated that FWA activities have had an impact on contraceptive adoption, continuity, and expanding choice (Simmons et al. 1988; Phillips et al. 1993; Hossain and Phillips 1996; Phillips et al. 1989a and 1989b). Even in the long term, after two decades of operation, the FWA program has an impact on contraceptive use (Phillips et al. 1996). The quality of exchanges, as measured by the time outreach workers spend with clients and the content of encounters, affects the contraceptive acceptance rate and the continuity of use (Koenig et al. 1997). According to recent estimates, about 85 percent of all contraceptive pill supplies are provided by field-workers (Streatfield et al. 1997). 
3 See Phillips et al. (1996), Cleland et al. (1994), and Larson and Mitra (1992). Research has noted ways in which the activities of FWAs may have indirectly enhanced the status of women. Because FWA workers benefit from cash wages and because FWAs are so numerous and so prominent as role models, their work may have enhanced the status of women more generally (Kak and Narasimhan 1992; Simmons et al. 1992). Moreover, the status of women in general may be enhanced by fertility control. For example, see Davis (1984), Keyfitz (1986), Kak and Narasimhan (1992), Simmons and Mita (1992), and Hoque and Murdock (1997).

4 See Schuler et al. (1995), which investigation of the social impact of family planning is a component of a more general investigation of the gender impact of micro-credit schemes. See Schuler and Hashemi (1993a and 1993b), Schuler (1994), Schuler and Hashemi (1994), and Meekers et al. (1992).

5 Various clients' complaints are reported in the study. First, an over-reliance on village workers was reported; hospital- and clinic-based services could deal more effectively with side effects and other clinical needs. Second, contraceptive choice is constrained by a home-based service system. FWAs provide contraceptive pills and little else. Third, clients are dependent upon FWAs, and provider dependency is associated with discontinuation and other problems. Fourth, fears concerning contraceptive methods are not allayed by the home-service system. A more comprehensive information system is needed. Fifth, side effects are not treated and are poorly dealt with in a home-based system. These sorts of observations have also arisen in reviews of the clinical system, however, and ending a home-based service-delivery system is less likely to address the problems noted in the 
Schuler et al. study than is simply changing the venue where such problems arise. Most of the problems noted in the review have been key rationales for developing the FWA program. Adding village workers to a program that serves women who are often immobile creates a new tier of counseling and information that clinic patients tend to need. Moreover, contraceptive choice is expanded by FWAs who provide nonclinical methods in a system that has traditionally emphasized sterilization and use of the IUD. The rate of practice of traditional contraception is higher for women visited by FWAs than it is for women who are not visited. For a discussion of this issue, see Khan and Rahman (1997). In general, the FWA program has reduced program reliance on permanent contraception (see Khan and Rahman 1997; Phillips et al. 1989a). Further expansion of choice has been introduced by training FWAs to provide injectable contraceptives (Phillips et al. 1989a).

6 The International Conference on Population and Development (Cairo, 1994) fostered international interest in developing gender criteria for evaluating program success and impact (United Nations 1994).

7 The comprehensive family planning program in Bangladesh has transformed the culture of contraception in Bangladesh (Schuler et al. 1996). Social research has illustrated ways in which the FWA program has contributed to this development (Kak and Narasimhan 1992; Simmons et al. 1992; Simmons and Mita 1992).

8 The Extension Project was originally designed to test the hypothesis that successful strategies of the Matlab Family Planning and Health Services Project could be implemented by the Ministry of Health and Family Welfare in two districts of Bangladesh (Phillips et al. 1984). Research strategies of the project have evolved over time so that current operations test 
new Government of Bangladesh policies directly rather than the replicability of Matlab operations (Haaga and Maru 1996). For the duration of the Extension Project, data-collection systems have monitored FWA outreach activities and household exposure to worker visits (Clark et al. 1986; Mozumder et al. 1991).

9 Women of higher status might be more accommodating to a visiting family welfare assistant, leading FWAs to contact higher-status clientele selectively. This type of selective outreach strategy has been established in analyses by Arends-Kuenning (1997a and 1997b).

10 Various studies have shown ways in which the FWA service regimen should be broadened or improved to include health care or other activities. A need exists for supervisory and management systems to improve the cooperation between health and family planning workers. The selectivity of FWA outreach is an additional problem area. For example, Arends-Kuenning has shown that workers' visits were most effective when the women contacted were uneducated or poor (Arends-Kuenning 1997a and 1997b). Analysis of program activity, however, showed a statistically significant pattern of selectivity in workers' activity and program assignment of workers. Outreach workers tend to select better-educated women in the course of household visitation rounds; program worker-assignment policies tend to deprive poor areas of outreach activity. The full potential for the program to improve equity is not realized. A second area concerns efficiency. Various studies have demonstrated that FWA outreach is more efficient and effective if it is conducted in the context of male outreach or group motivational activities (for example, see Kincaid et al. 1993). Outreach to groups and to men may improve the gender impact of the FWA initiative. 
11 The process of replacing paid outreach workers who are women with male workers has already begun in nongovernmental agency service organizations. For example, Pathfinder International has terminated paid female outreach workers and converted their roles to unpaid volunteer "depot holders." The new depot "supervisors" who are being hired are mainly men. This strategic shift has been tantamount to changing the paid work force from female to male workers. This change is justified by donor interest in cutting costs, increasing impact, and improving gender effects-a strategic response to the Schuler et al. analysis (see, for example, the USAIDsponsored review by the POPTECH Project [POPTECH 1995]) and policy deliberations of Pathfinder International [Pathfinder International 1991]. Pathfinder International's strategic changes illustrate the political risks for women associated with well-articulated, but poorly researched criticisms of programs staffed by women. In settings where hiring practices of bureaucracies have traditionally discriminated against women, unfounded gender-based criticisms of programs can be particularly damaging to women.

\section{References}

Abdullah, Tahrunnessa Ahmed and Sondra A. Zeidenstein. 1982. Village Women of Bangladesh: Prospects for Change. New York: Pergamon Press.

Adnan, Shapan. 1993. "Birds in a cage: Institutional change and women's position in Bangladesh." In Women's Position and Demographic Change. Eds. N. Federici, K.O. Mason, and S. Sogner. Oxford: Clarendon Press. Pp. 285-318.

Amin, Sajeda. 1997. "The poverty-purdah trap in rural Bangladesh: Implications for women's roles in the family." Development and Change 28 (2): 213-233.

Arends-Kuenning, Mary. 1997a. "How Do Family Planning Workers' Visits Affect Women's Contraceptive Behavior in Bangladesh?” Policy Research Division Working Paper No. 99. New York: Population Council. 
1997b. "The Equity and Efficiency of Doorstep Delivery of Contraceptives in Bangladesh.” Policy Research Division Working Paper No. 101. New York: Population Council.

Balk, Deborah. 1991. Parity and Imparity: Individual and Community Aspects of Fertility and Women's Status in Rural Bangladesh. Berkeley: University of California Department of Economics.

- 1994. "Individual and community aspects of women's status and fertility in rural Bangladesh.” Population Studies 48(1): 21-45.

—. 1997. "Defying gender norms in rural Bangladesh: A social demographic analysis." Population Studies 51(2): 153-172.

Cain, Mead, Syeda Rokeya Khanam, and Shamsun Nahar. 1979. "Class, patriarchy, and women's work in Bangladesh." Population and Development Review 5(3): 405-438.

Clark, Samuel, Mian Bazle Hossain et al. 1986. First report on visits, topics discussed, and services received from government health and family planning workers by eligible women in two subdistricts and two comparison areas from April 1984 to March 1985. Dhaka: Maternal and Child HealthFamily Planning Project, International Centre for Diarrhoeal Disease Research, Bangladesh.

Cleland, John, James F. Phillips, Sajeda Amin, and Gholam Mostafa Kamal. 1994. The Determinants of Reproductive Change in Bangladesh: Success in a Challenging Environment. Washington, DC: The International Bank for Reconstruction and Development/The World Bank.

Curtin, Leslie B. 1982. "Status of women: A comparative analysis of twenty developing countries." Reports on the World Fertility Survey No. 5. Washington, DC: Population Reference Bureau.

Davis, Kingsley. 1984. "Wives and work: The sex role revolution and its consequences." Population and Development Review 10(3): 397-417. 
Haaga, John G. and Rushikesh M. Maru. 1996. "The effect of operations research on program changes in Bangladesh." Studies in Family Planning 27(2): 76-87.

Hoque, Md. Nazrul and Steve H. Murdock. 1997. "Socioeconomic development, status of women, family planning, and fertility in Bangladesh: A district level analysis." Social Biology 44(3-4): 179-197.

Hossain, Mian Bazle and James F. Phillips. 1996. "The impact of outreach on the continuity of contraceptive use in rural Bangladesh." Studies in Family Planning 27(2): 98-106.

Kabeer, Naila. 1988. "Subordination and struggle: Women in Bangladesh.” New Left Review 168: 95-121.

Kak, Lily and S. Narasimhan. 1992. "The impact of family planning employment on field workers' lives: A strategy for measuring empowerment." Washington, DC: Centre for Development and Population Activities.

Keyfitz, Nathan. 1986. "The family that does not reproduce itself." Population and Development Review 12 (Supplement): 139-154.

Khan, Mehrab Ali and Mizanur Rahman. 1997. "Determinants of contraceptive method choice in rural Bangladesh." Asia-Pacific Population Journal 12(3): 65-82.

Kincaid, D. Lawrence, A. Das Gupta, S.N. Mitra, E. Whitney, M. Senior, S.H. Yun, and Ernest Messiah. 1993. "Community networks and family planning promotion: Impact of the 'Jiggasha' approach in Trishal, Bangladesh." Paper presented at the annual meeting of the American Public Health Association, San Francisco, 24-28 October.

Larson, Ann and S.N. Mitra. 1992. "Family planning in Bangladesh: An unlikely success story.” International Family Planning Perspectives 18(4): 123-129.

Lindenbaum, Shirley. 1968. "Women and the left hand: Social status and symbolism in East Pakistan." Mankind 6(11): 537-544. 
Meekers, Dominique, Sidney Ruth Schuler, and Syed Hashemi. 1992. "Can Credit Programs for Women Affect Reproductive Behavior? The Case of Rural Bangladesh.” Working paper. University Park, PA: Pennsylvania State University, Population Research Institute.

Mozumder, A.B.M. Khorshed Alam, Michael A. Koenig, James F. Phillips, and Shahed Murad. 1991. "The Sample Registration System: An innovative system for monitoring demographic dynamics in rural Bangladesh.” AsiaPacific Population Journal 5(3): 63-72.

Pathfinder International. 1991. Sustainability of Family Planning NGOs in Bangladesh: Workshop Report. Comilla, Bangladesh: Bangladesh Academy for Rural Development.

Phillips, James F., Mian Bazle Hossain, Ruth Simmons, and Michael A. Koenig. 1993. "Worker-client exchanges and contraceptive use in rural Bangladesh." Studies in Family Planning 24(6): 329-342.

Phillips, James F., Mian Bazle Hossain, and Mary Arends-Kuenning. 1996. "The long-term demographic role of community-based family planning in rural Bangladesh." Studies in Family Planning 27(4): 204-219.

Phillips, James F., Mian Bazle Hossain et al. 1989a. “A case study of contraceptive introduction: Domiciliary depot-medroxy progesterone acetate (DMPA) services in Bangladesh." In The Demographic and Programmatic Consequences of New Contraceptives. Eds. S. Segal, Amy O. Tsui, and S. Rogers. New York: Plenum Press.

1989b. "Improving the climate of choice in rural Bangladesh: The effect of organizational change on contraceptive behavior in rural Bangladesh." In Choosing a Contraceptive: Factors in Method Choice in Asia and the United States. Eds. R.A. Bulatao, J.A. Palmore, and S.E. Ward. Boulder, CO: Westview Press: 212-236.

Phillips, James F., Ruth Simmons, George B. Simmons, and Md. Yunus. 1984. "Transferring health and family planning service innovations to the public 
sector: An experiment in organizational development in Bangladesh. ” Studies in Family Planning 15(2): 62-73.

POPTECH. 1995. The Bangladesh Family Planning and Health Services Project Evaluation Report. Arlington, VA: The POPTECH Project.

Schuler, Sidney Ruth. 1994. "Empowerment and family planning in Bangladesh." Network 15(1): 16-17.

Schuler, Sidney Ruth and Syed M. Hashemi. 1993a. Defining and Studying Empowerment of Women: A Research Note from Bangladesh. Boston: John Snow International Research and Training Institute.

1993b. Effects of Rural Credit Programs and Women's Empowerment on Use of Contraception in Bangladesh. Boston: John Snow International Research and Training Institute.

- 1994. "Credit programs, women's empowerment, and contraceptive use in rural Bangladesh." Studies in Family Planning 25(2): 65-76.

Schuler, Sidney Ruth et al. 1995. "Bangladesh's family planning success story: A gender perspective." International Family Planning Perspectives 21(4): 132-166.

- 1996. "The advent of family planning as a social norm in Bangladesh: Women's experiences." Reproductive Health Matters 7: 66-78.

Simmons, Ruth and Rezina Mita. 1992. "Women's status and family planning in Bangladesh: An analysis of focus group data." Bangkok: The Population Council.

Simmons, Ruth, Laila Baqee, Michael A. Koenig, and James F. Phillips. 1988. "Beyond supply: The importance of family planning workers in rural Bangladesh." Studies in Family Planning 19(1): 29-38.

Simmons, Ruth, Rezina Mita, and Michael A. Koenig. 1992. "Employment in family planning and women's status in Bangladesh." Studies in Family Planning 23(2): 97-109. 
Streatfield, Kim, Sayyied Kabir, Kanta Jamil, Barbara Janowitz, and Naushad Faiz. 1997. Increasing Financial Sustainability of Family Planning Service Delivery in Bangladesh. Dhaka: The Population Council.

United Nations. 1995. Programme of Action adopted at the International Conference on Population and Development, Cairo, 5-13 September 1994. ST/ESA/SER.A/149. New York.

White, Sarah C. 1992. Arguing with the Crocodile: Gender and Class in Bangladesh. Dhaka: University Press. 


\title{
POLICY RESEARCH DIVISION WORKING PAPERS
}

\author{
Recent Back Issues
}

1996

*83 Sajeda Amin, Ian Diamond, and Fiona Steele, "Contraception and religious practice in Bangladesh."

84 John B. Casterline, Aurora E. Perez, and Ann E. Biddlecom, "Factors underlying unmet need for family planning in the Philippines."

85 Geoffrey McNicoll, "Governance of fertility transition: Regularity and duress."

*86 John Bongaarts, "Population pressure and the food supply system in the developing world."

87 Sajeda Amin, "Family structure and change in rural Bangladesh."

*88 John Bongaarts and Susan Cotts Watkins, "Social interactions and contemporary fertility transitions."
*89 Cynthia B. Lloyd and Mark R. Montgomery, "The consequences of unintended fertility for investments in children: Conceptual and methodological issues."

* 90 Zeba Sathar and Sonalde Desai, "Work patterns in rural Pakistan: Intersections between gender, family, and class."

*91 Mark R. Montgomery, "Learning and lags in mortality perceptions."

92 Ann E. Biddlecom, John B. Casterline, and Aurora E. Perez, "Men's and women's views of contraception."
93 James F. Phillips, Fred N. Binka, Martin Adjuik, Alex Nazzar, and Kubaze Frank Adazu, "The determinants of contraceptive innovation: A case-control study of family planning acceptance in a traditional African society."
94 John Bongaarts and Sajeda Amin, "Prospects for fertility decline and implications for population growth in South Asia."

95 Barbara S. Mensch and Cynthia B. Lloyd, "Gender differences in the

* No longer available 
schooling experiences of adolescents in low-income countries: The case of Kenya."

96 Martin Brockerhoff and Ellen Brennan, "The poverty of cities in the developing world."

97 Carol E. Kaufman, "Reproductive control in South Africa."

98 John Bongaarts, "Trends in unwanted childbearing in the developing world."

99 Mary Arends-Kuenning, "How do family planning workers' visits affect women's contraceptive behavior in Bangladesh?"

100 Mark R. Montgomery and Cynthia B. Lloyd, "Excess fertility, unintended births, and children's schooling."
101 Mary Arends-Kuenning, “The equity and efficiency of doorstep delivery of contraceptives in Bangladesh."

102 Sajeda Amin, Ian Diamond, Ruchira T. Naved, and Margaret Newby, "Transition to adulthood of female factory workers: Some evidence from Bangladesh."

*103 Margaret E. Greene and Ann E. Biddlecom, "Absent and problematic men: Demographic accounts of male reproductive roles."

104 Michael P. Todaro, "Urbanization, unemployment, and migration in Africa: Theory and policy."

105 Geoffrey McNicoll, "Population and poverty: A review and restatement."
106 Sajeda Amin and Gilda Sedgh, "Incentive schemes for school attendance in rural Bangladesh."

107 Martin Brockerhoff and Paul Hewett, "Ethnicity and child mortality in subSaharan Africa."

108 Ann E. Biddlecom and Bolaji M. Fapohunda, "Covert contraceptive use: Prevalence, motivations, and consequences."

109 John Bongaarts and Griffith Feeney, "On the quantum and tempo of fertility."
110 Barbara S. Mensch, Daniel Bagah, Wesley H. Clark, and Fred Binka, "The changing social environment for adolescents in the Kassena-Nankana District of northern Ghana: Implications for reproductive behavior."

111 Martin Brockerhoff and Ann Biddlecom, "Migration, sexual behavior, and HIV diffusion in Kenya."

112 Zeba A. Sathar and John B. Casterline, "The onset of fertility transition in Pakistan." 
113 Geoffrey McNicoll, "Government and fertility in transitional and post-transitional societies."

114 John Bongaarts, "Fertility and reproductive preferences in post-transitional societies."

115 Fiona Steele, Sajeda Amin, and Ruchira T. Naved, "The impact of an integrated micro-credit program on women's empowerment and fertility behavior in rural Bangladesh."

116 Cynthia B. Lloyd, Barbara S. Mensch, and Wesley H. Clark, "The effects of primary school quality on the educational participation and attainment of Kenyan girls and boys."

117 Sajeda Amin and Cynthia B. Lloyd, "Women's lives and rapid fertility decline: Some lessons from Bangladesh and Egypt."

118 James F. Phillips and Mian Bazle Hossain, "The impact of family planning household service delivery on women's status in Bangladesh." 